ПОВЫШЕНИЕ ЭФФЕКТИВНОСТИ ПРОЦЕССА ГАШЕНИЯ КОЛЕБАНИЙ МЕХАНИЧЕСКИХ

\title{
СИСТЕМ
}

Е. А. Милованова

Иркутский государственный университет

путей сообщения

(Иркутск, Россия)

\section{IMPROVING THE EFFICIENCY OF THE PROCESS OF DAMPING MECHANICAL SYSTEMS}

Evgeniya A. Milovanova

Federal State Budget Educational Institution of Higher

Education Irkutsk State Transport University

(Irkutsk, Russia)

По данным ООО «ТМХ-Сервис» (подразделения ЗАО «Трансмашхолдинг») при выполнении сервисного обслуживания локомотивов высокий процент отказов механической части приходится на тяговую передачу, среди которых особо отмечаются: разрывы кожухов по сварочным швам, излом болтового крепления кожуха, повреждение резьбы в остове тяговых двигателей. При этом, проблема обрыва болтов кожуха зубчатой передачи за последние годы приобрела массовый характер.

Причины сложившейся ситуации видятся, в том числе, в повышении жесткости верхнего строения пути, связанной с увеличением общей протяженности пути, использующей железобетонные шпалы, что наглядно подтверждается рис.1 и рис.2. 


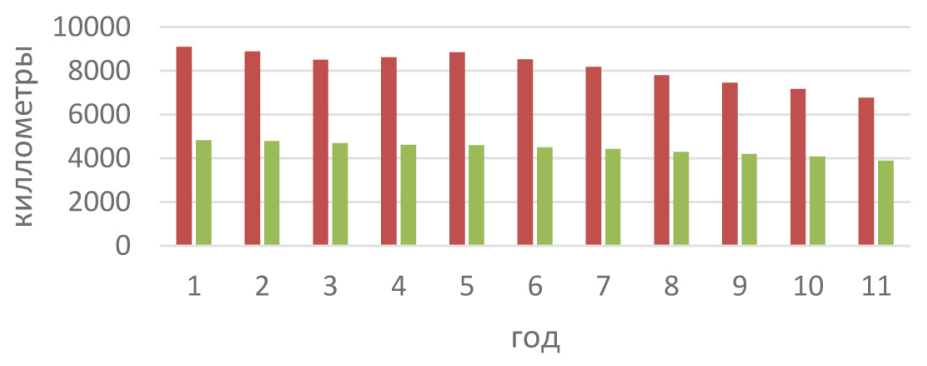

口Дорога,км घ БАМ, км

Рис.1. Протяженность пути с деревянными шпалами на Восточно-Сибирской железной дороге за период 2006-2016 года.
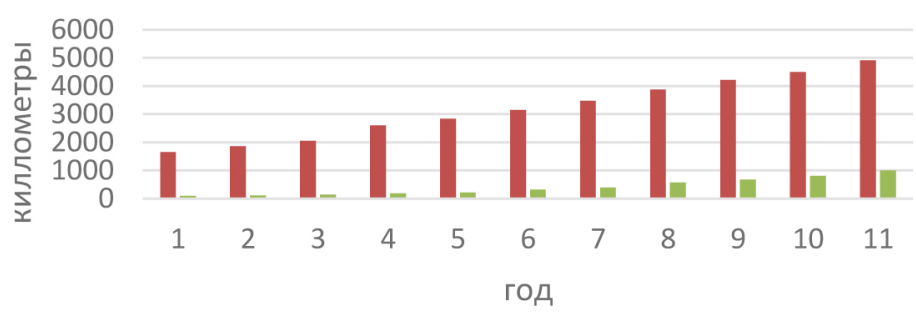

- Дорога,км БАМ, км

Рис.2. Протяженность пути с железобетонными шпалами на Восточно-Сибирской железной дороге за период 2006-2016 года. 
Интересна, в связи с этим, идея разработки и реализации устройств, повышающих эффективность процесса гашения колебаний механических систем, что, несомненно, актуально с учетом развивающейся в нашей стране системы высокоскоростных магистралей.

На основании имеющегося опыта, а так же обзора технических решений, направленных на повышение качества демпфирования в подвижном составе, разработана принципиальная схема гидравлического гасителя нового типа. Известно принятое в качестве прототипа «Устройство для гашения колебаний в железнодорожном транспортном средстве, выполняющем грузовые перевозки» [1], предназначенное для применения в комплексной транспортной единице для перевозки грузов [2], использующее несамотормозящие винтовые кинематические пары в фрикционном контакте основных и, расположенных между ними, промежуточных конструктивных элементов, в котором камеры заполненной гидросмесью внутренней полости корпуса соединены дроссельными каналами, выполненными в промежуточном элементе.

Представленный гидрогаситель относится к техническим средствам виброзащиты и имеет возможность быть использованным, к примеру, для нейтрализации негативного воздействия колебательных процессов в транспортных средствах (TC).

Обозначенная цель достигается тем, что в устройстве для гашения колебаний, состоящем из двух частей, зеркально расположенных относительно срединной поперечной плоскости симметрии и содержащем, в качестве основных несущих элементов конструкции, два штока, образующие с опорными поверхностями конструкции транспортного средства цилиндрические кинематические пары и взаимодействующие, при посредстве несамотормозящих винтовых кинематических пар правой и левой резьбы соответственно, с охватывающими их двумя цилиндрическими стаканами, соединёнными втулочной цилиндрической муфтой, составляюшей с боковыми поверхностями стаканов жёсткое самотормозящее винтовое соединение правой и левой резьбы соответственно, образуя корпус устройства, камеры внутренней полости которого заполнены гидросмесью и связаны между собой дроссельными 
каналами, расположенными вдоль винтовых линий кинематических пар, а их стенками служат поверхности участков профилей резьбы, ограниченные наружными и внутренними диаметрами сопряжённых профилей.

Технический результат применения предлагаемого решения заключается в повышении степени динамической устойчивости процесса гашения колебаний автономным устройством.

\section{Библиографический список}

1. Устройство для гашения колебаний в железнодорожном транспортном средстве, выполняющем грузовые перевозки. Патент РФ № 2569970, Бюл. № 34. 2015.

2. Комплексная рабочая транспортная единица для грузовых перевозок. Патентная заявка РФ № 2015123228. 2015.

\section{Сведения об авторе:}

МИЛОВАНОВА Евгения Алексеевна, кандидат технических наук, доцент кафедры ЭПС, Иркутский государственный университет путей сообщения (ИрГУПС) E-mail: evakami@yandex.ru

\section{Information about authos:}

Evgeniya A. MILOVANOVA, Ph.D. (Tech), associate professor of the department EPS, Irkutsk State University of Railway Engineering (IrGUPS)

E-mail: evakami@yandex.ru 